\title{
Bearing Characteristics of Surrounding Rock of Deep Mining Roadway with Full and End Bolt Anchorages: A Comparative Numerical and Experimental Study
}

\author{
Wenbao Shi $\left(\mathbb{D},{ }^{1,2}\right.$ Yan Li $\left(\mathbb{D},{ }^{3}\right.$ Wanfeng Li $\left(\mathbb{D},{ }^{4}\right.$ and Shihui Li ${ }^{4}{ }^{4}$ \\ ${ }^{1}$ School of Energy and Security, Anhui University of Science and Technology, Huainan 232001, China \\ ${ }^{2}$ Safe and Efficient Mining of Coal Mines, Key Laboratory of Ministry of Education Jointly Built By The Ministry of Education, \\ Huainan 232001, China \\ ${ }^{3}$ College of Mechanical and Electrical Engineering, Huainan Normal University, Huainan 232001, China \\ ${ }^{4}$ Huainan Mining (Group) Corporation Limited, Huainan 232001, China \\ Correspondence should be addressed to Yan Li; 1960526430@qq.com
}

Received 4 September 2020; Revised 6 December 2020; Accepted 28 December 2020; Published 16 January 2021

Academic Editor: Emanuele Brunesi

Copyright (C) 2021 Wenbao Shi et al. This is an open access article distributed under the Creative Commons Attribution License, which permits unrestricted use, distribution, and reproduction in any medium, provided the original work is properly cited.

\begin{abstract}
The support strength of surrounding rock in deep mining roadways can be significantly improved by replacing the end bolt anchorage with a full one. The support effects of both types of anchorage and the axial stress distribution characteristics in anchored bolt bodies were assessed via the indoor pull-out test, simulated via the FLAC3D software, and verified by field measurements. The stability and variation patterns of the axial force, as well as the evolution law of bearing characteristics of surrounding rock, were analyzed. The results indicate that the polymorphic deformations of deep mining roadway surrounding rock and the bolt support body interact synchronously. The axial force evolution trend in bolt bodies with end anchorage revealed by field tests was consistent with the laboratory test results, in contrast to that of full anchorage. Although stress distribution laws in both sides of the mining roadway were the same for both types of anchorage, the vertical stress peak and damage range of fullanchored surrounding rock slightly exceeded those of the end-anchored one. The anchored area bearing a higher load alleviated the stress concentration of the surrounding rock. Since the deformations in fully and end anchored surrounding rocks increased gradually and sharply, respectively, the full anchorage is more conducive to deformation moving control of deep mining roadway surrounding rock. The research results can provide theoretical guidance for the design and construction of deep mining roadway bolt support.
\end{abstract}

\section{Introduction}

After the tunnel is excavated in the mining process, the surrounding rock's initial crustal stress field is perturbed and the stress is redistributed. Surrounding rock (SR) near the tunnel surface begins to enter the state of plastic failures, forming the so-called loose rings $[1,2]$. To improve the bearing performance of SR and control the deformation of SR, bolts (cables) are often used to strengthen the SR actively. This support method generates effective radial constraints on SR within a certain range of tunnels, improves the SR strength, and makes SR an effective bearing body to jointly resist the deformation and fracture of SR outside the loose ring and maintain the safety and stability of tunnels [3, 4]. With an increase in coal mining depth, the SR of deep mining roadway is affected by high crustal stress and mining disturbances, exhibiting large deformations, high ground pressure, and nonlinear failure characteristics of support $[5,6]$. In this context, the end anchorage replacement by full bolt anchorage for improving the support strength became a hotspot in engineering applications [7]. Therefore, clarifying the strengthening effect of the bolt-anchored body and bearing characteristics of SR under different anchorages can substantiate the optimal support design of deep mining roadways. 


\section{Related Studies}

The bearing mechanism of anchored SR has been in the focus of many researchers. Unreasonable anchorage states decrease bolts' overall elongation rate and make them easily break at the end. For this reason, Seunghwan et al. [8] studied the influence of bolts on the anchoring performance of limestone and shale and reported that bolts could improve the shear resistance of joint surfaces of rock masses. Marini and Bellopede [9] analyzed the relationship between the shear stiffness of jointed rock mass and the number of bolts, elastic modulus, inclination, rock deformation parameters, and cross-sectional geometric parameters through rock mass anchoring tests. Akisanya and Ivanović [10] studied the anchoring effect of end anchoring bolts on different rock materials. They pointed out that rock mass's deformability has a strong effect on the shear resistance of anchored rock mass. Hofmann et al. [11] conducted shear tests of anchored concrete and revealed the effect of bolt body material, size, and rock type on the anchorage body's shear strength. Huang et al. [12] studied the load transfer characteristics of rock masses with different strengths under the effect of full anchoring bolts. They reported that the strength and prestress of rock masses greatly influenced the failure characteristics of the anchorage body. Zhao et al. [13] performed the comprehensive analysis of anchored specimens' mechanical properties and reported that they were related to the properties of bolt materials. The above studies were mainly focused on the effect of a single factor on the anchoring performance. It is difficult to realize the multimorphic deformation simulation of the mining roadway SR on-site and effectively describe the pattern of SR mining disturbances' effect on the strength of bolt-anchored rock mass.

To analyze the influence of the bolt-anchored body on bearing characteristics of SR more reasonably, several scholars adopted the finite element method (FEM) to study the stability of bolt-anchored SR, which took into account the bolt material and mechanical parameters [14-16], anchoring angle, and tunnel section shape [17-19]. Lyu et al. [20] took the roof of a rectangular coal roadway as an example and simulated the supporting effect of the roof SR for various bolt layouts. They revealed the interaction mechanism between bolts and SR. Nagai et al. [21] considered the influence of different bolt installation angles, bolt lengths, and crustal stress levels, studied the mechanical effects of bolts, and proved out that bolts could effectively improve the stress state of SR and reduce the stress concentration coefficient around the tunnel. Sik [22] refined the simulation of bolt support unit in the existing numerical calculation software, assuming that the bond strength of bolts depended on the stress of SR and analyzed the mechanical effect of SR on the tunnel excavation surface under the effect of bolt support. Chen et al. [23] analyzed the stress field distribution characteristics of SR under different bolt anchorages. Zhao et al. [24] established the constitutive model of anchored intermittent jointed rock mass and its damage evolution equation and verified the constitutive model's validity through simulation analysis examples. In the above FEM simulations, the refined tunnel model is established, and the stress distribution characteristics of different bolt anchoring methods are analyzed based on the anchoring mechanism. However, the adaptability and limitations of different bolt anchoring methods are lack of research, and it is difficult to select a reasonable anchor support mode according to the actual geological conditions.

In summary, the available theoretical studies, laboratory tests, and numerical simulations analyzed various factors affecting the anchorage bodies' characteristics. However, there are quite scarce research results on bolt force characteristics under different anchorages. The bearing characteristics of full-anchored SR lack comparative studies, and the distribution parameters of the axial forces acting on bolts are also unclear. Based on this, field comparative tests and numerical simulations are used to study force characteristics of full- and end-anchored bolts and SR stability. Their aim is revealing the strengthening mechanism and bearing capacity of SR under different anchorages, as well as the effect of bearing characteristics of anchorage bodies on SR stability under different anchorages.

\section{Experimental}

The laboratory test of bolt drawing is carried out, and the scheme is as follows:

(1) The bolt used in the experiment is a mining lefthanded screw thread steel bolt; the size is $22 \mathrm{~mm} \times 2500 \mathrm{~mm}$, a total of 8 anchors. Each bolt is cut into a groove of $2 \mathrm{~mm}$ deep and $2 \mathrm{~mm}$ wide at the end of the bolt thread to place the optical cable, and 10 grating sensors are arranged. The distance between the sensor and the end of the bolt thread is shown in Figure 1. The optical fiber anchor rod (as shown in Figure 2(a)) is used for four groups of end anchorage pull-out tests and is used for full-length anchor four groups were fixed drawing test.

(2) Z2560 resin anchoring agent is used as the anchoring agent. One anchoring agent is used for end anchoring and three anchoring agents are used for fulllength anchoring.

(3) The same simulated surrounding rock test block is used in the pull-out test; the size of the test block is $200 \mathrm{~mm} \times 200 \mathrm{~mm} \times 2500 \mathrm{~mm}$, as shown in Figure 2 . The selected materials of the surrounding rock test block are cement, sand, stone, and water, and the mass ratio relationship is $0.38: 1: 1.11: 2.72$.

The distribution of the rod axial force obtained via the bolt drawing test is shown in Figures 3(a) and 3(b). As observed, the axial force of the free section of end-anchored bolts was approximately equal to the maximum axial force of the bolt. The anchored section's axial force exhibited a decreasing trend, and the axial force of the bolt-free section exceeded that of the anchored section. The bolt body's axial force changed very little during the initial drawing, while that of the anchored section presented a linearly decreasing trend. With an increase in the bolt drawing force, the increasing trend of the bolt anchoring section's axial force became more pronounced. 


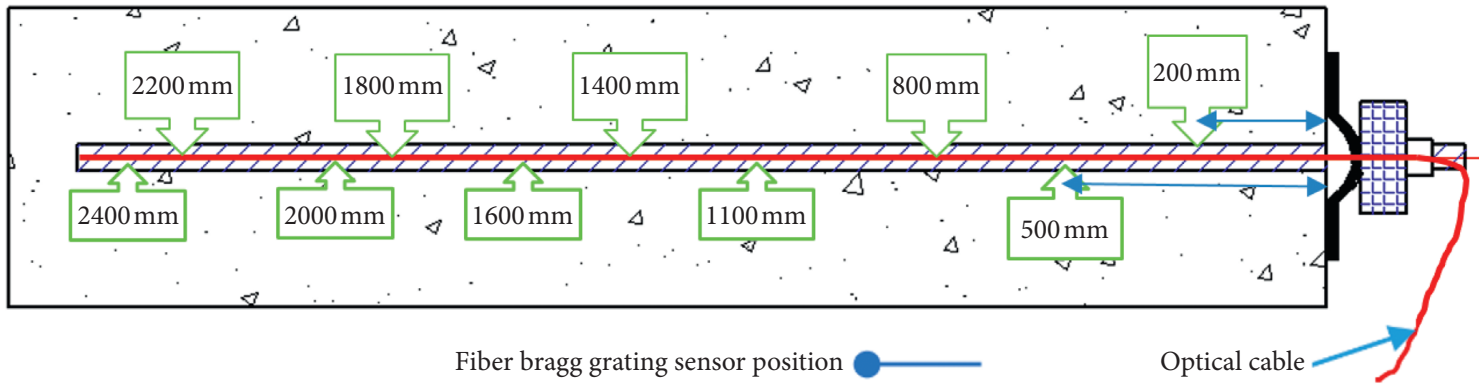

Figure 1: Schematic diagram of bolt grooving.

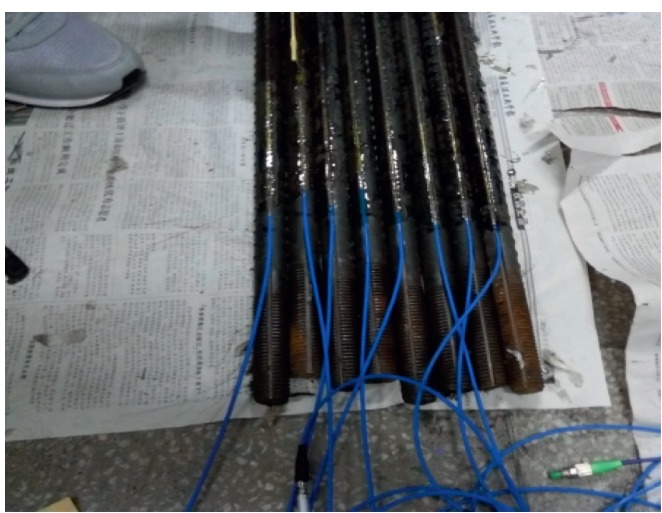

(a)

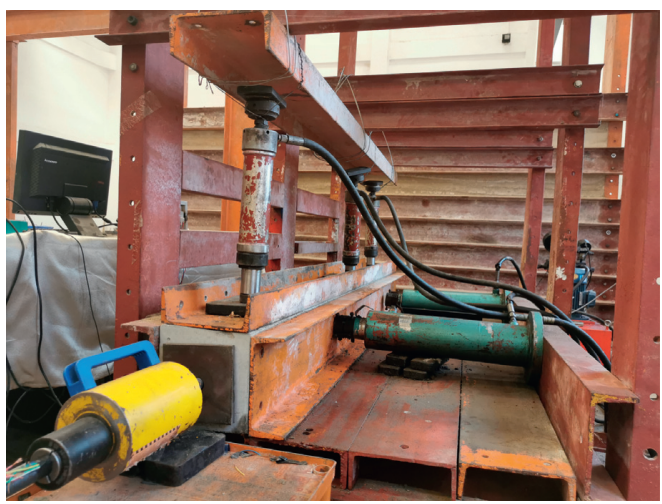

(c)

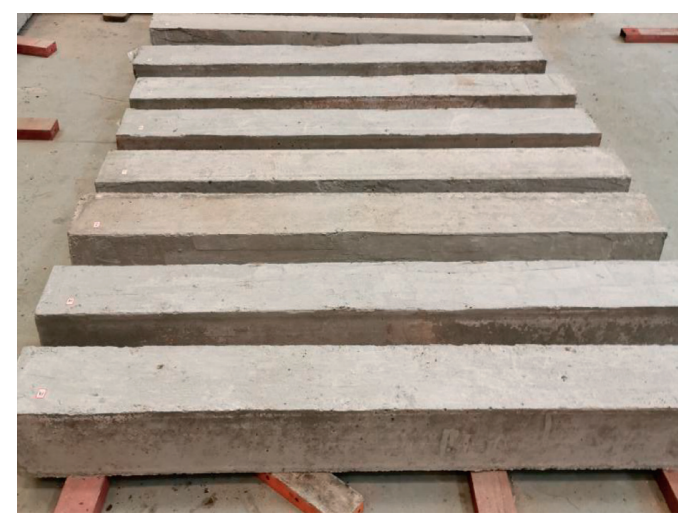

(b)

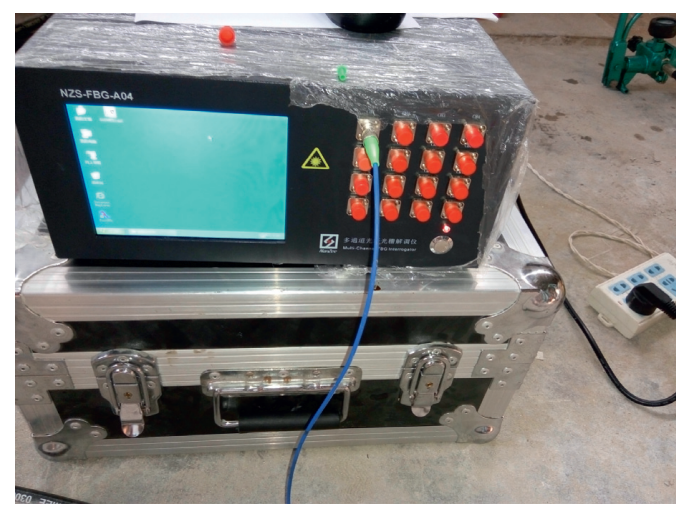

(d)

FIgURE 2: Bolt drawing test. (a) Grating force-measuring bolt. (b) Simulating surrounding rock block. (c) Bolt drawing test platform. (d) Fiber grating demodulator.

The full anchoring bolt's axial force reached the maximum near the pallet, and the transmission range of the drawing force was gradually reduced in the full-anchored bolt. When the drawing force was increased, the axial force in the bolt anchoring zone was still small, approaching zero at the head position close to the bolt.

\section{Simulation Analysis of Bolt Anchorage Length in Deep Mining Roadway}

4.1. Project Overview. The 1131 (1) working face of zhujidong coal mine has a mining height of about $1.9 \mathrm{~m}$. The coal seam is 11-2 Coal, with a thickness of $0.7-1.6 \mathrm{~m}$ and an average thickness of $1.2 \mathrm{~m}$. The coal seam structure is stable and simple. The direct roof of the working face is mudstone with an average thickness of $17.7 \mathrm{~m}$; the main roof is fine sandstone with an average thickness of $2.3 \mathrm{~m}$; the direct bottom is mudstone with an average thickness of about $5.8 \mathrm{~m}$. The support mode of transportation roadway is bolt (cable) + rhombic metal mesh support, roof bolt MG400, $\Phi$ $22 \times 2800 \mathrm{~mm}$, spacing $750 \times 800 \mathrm{~mm}$; side bolt $\mathrm{mg} 335$, and $\Phi 22 \times 2500 \mathrm{~mm}$ (full thread) $700 \times 800 \mathrm{~mm}$; anchor cable length $6300 \mathrm{~mm}$, roof diamond mesh $10 \# 5600 \times 1000 \mathrm{~mm}$, and side diamond mesh $103400 \times 1000 \mathrm{~mm}$.

4.2. Calculation Model and Parameters. The finite difference software FLAC3D is used to simulate and analyze the mechanical response characteristics of roadway surrounding 


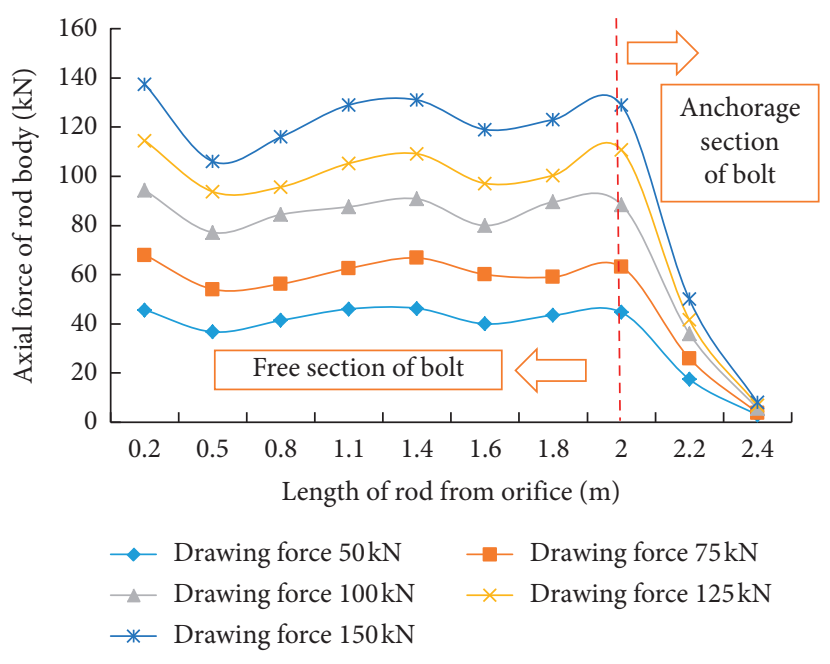

(a)

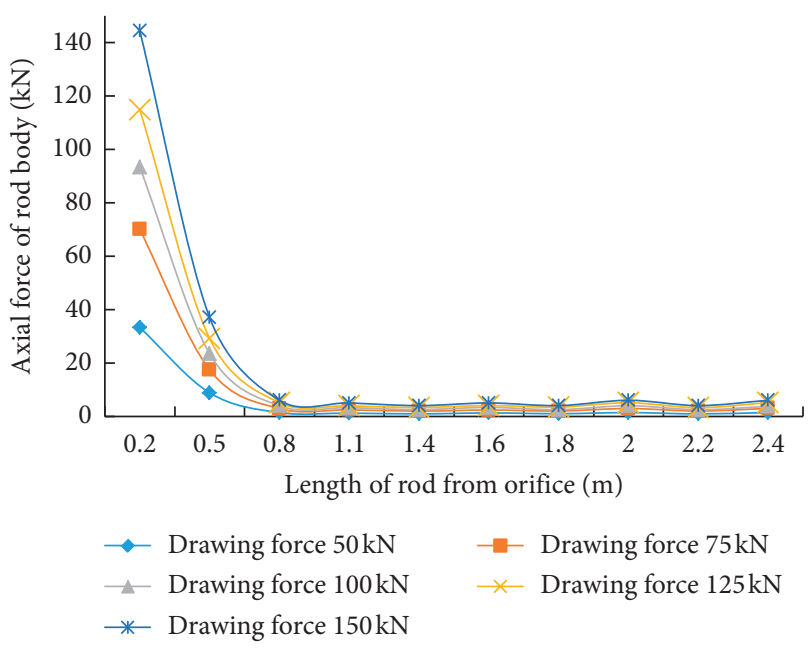

(b)

FIGURE 3: Bolt axial force versus rod length under different anchorages. (a) End anchorage. (b) Full anchorage.

rock under different anchorage lengths. The supporting effect of end bolt support condition and full-length anchor support condition is compared and analyzed, and the influence characteristics of bolt anchoring mode on surrounding rock stability of roadway is further explored.

Based on the geological conditions of 1131 (1) working face in Zhujidong coal mine, a three-dimensional numerical calculation model with strike length of $300 \mathrm{~m}$, horizontal length of $310 \mathrm{~m}$, and height of $200 \mathrm{~m}$ was established. The stress distribution and deformation of roadway surrounding rock under bolt end anchoring and full-length anchoring were simulated under the same support parameters. The calculation model is shown in Figure 4. At the same time, the vertical displacement of the bottom of the model and the horizontal displacement of the side of the model are limited in the calculation process.

The mechanical parameters used in the numerical simulation correspond to the physical and mechanical parameters of the overlying rock of the 1131(1) working face in the Zhujidong Coal Mine, as listed in Table 1.

4.3. Numerical Simulation Results. The full and end anchorages' simulation results are shown in Figure 5. The results indicate that, under mining disturbances, the stress distribution at both sides of the mining roadway is only slightly affected by the SR's support strength. The stress distribution trend of mining disturbances under two working conditions is the same, but within the $0-30 \mathrm{~m}$ area of the mining integrated coal beside the tunnel, the distance between the stress peak and the working face under the full anchorage condition is slightly larger than that in the end one, and the vertical stress in this area under former condition slightly exceeds that under the latter one.

According to the simulation results, the section was made along the coal seam's inclination direction to obtain the mining roadway SR plastic failures at 5, 20,30, and $60 \mathrm{~m}$ in front of the working face under mining disturbances shown in Figure 6. At the distance of $60 \mathrm{~m}$ in front of the working face, the range of full- and end-anchored SR plastic failures is the same due to smaller mining effects, in which the damage depth of the left side is about $4.5 \mathrm{~m}$, the right side is about $5.0 \mathrm{~m}$, the roof is about $3 \mathrm{~m}$, and the bottom is about $4.5 \mathrm{~m}$. As the working face continues to advance, mining disturbances are enhanced, and the scope of SR plastic failures permanently increases. At $30 \mathrm{~m}$ in front of the working face, the deformation and damage range of full- and end-anchored SRs are the same; while at $20 \mathrm{~m}$ in front of the working face, the depth of SR plastic failures under both conditions has a significant increase, but the range of endanchored SR plastic failures is significantly higher than that of full-anchored ones. This phenomenon is more obvious at $5 \mathrm{~m}$ in front of the working face.

Comparing two working conditions, within $0-30 \mathrm{~m}$ in front of the working face, with the enhancement of the mining disturbance at the working face, the full anchorage significantly improves the SR bearing characteristics. The increase in the depth of SR plastic failures is significantly reduced. The bearing capacity of SR is significantly improved, and the full anchorage is more conducive to the stable control of the mining roadway SR.

\section{Field Test Monitoring}

In order to monitor the influence of different anchoring forms on the bearing characteristics of deep buried surrounding rock, combined with the specific geological conditions of 17102 (3) mining roadway in Pansan Coal Mine, the end anchoring support test within $30 \mathrm{~m}$ range and the full length anchoring support test within $30 \mathrm{~m}$ range are selected for the length of $60 \mathrm{~m}$ with little change in surrounding rock structure The force-measuring bolt and 


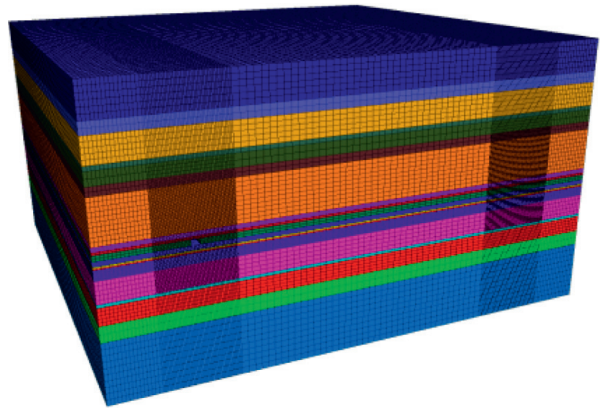

Figure 4: Three-dimensional calculation model.

TABLe 1: Physical and mechanical parameters of the rock used in the model.

\begin{tabular}{lccccccc}
\hline Rock type & $\begin{array}{c}\text { Density } \\
\left(\mathrm{kg} / \mathrm{m}^{3}\right)\end{array}$ & $\begin{array}{c}\text { Tensile } \\
\text { strength } \\
(\mathrm{MPa})\end{array}$ & $\begin{array}{c}\text { Compressive } \\
\text { strength }(\mathrm{MPa})\end{array}$ & $\begin{array}{c}\text { Elastic } \\
\text { modulus } \\
(\mathrm{GPa})\end{array}$ & $\begin{array}{c}\text { Poisson's } \\
\text { ratio }\end{array}$ & $\begin{array}{c}\text { Cohesion } \\
(\mathrm{MPa})\end{array}$ & $\begin{array}{c}\text { Internal friction angle } \\
\left({ }^{\circ}\right)\end{array}$ \\
\hline $\begin{array}{l}\text { Sandy mudstone } \\
\text { Medium-fine }\end{array}$ & 2638.43 & 4.88 & 83.62 & 9.99 & 0.27 & 27.08 & 29.46 \\
sandstone & 2629.79 & 4.21 & 106.289 & 13.729 & 0.308 & 32.96 & 34.32 \\
Mudstone & 2616.61 & 3.53 & 113.29 & 15.27 & 0.376 & 32.92 & 32.03 \\
Fine sandstone & 2892.1 & 1.896 & 45.225 & 5.75 & 0.172 & 34.96 & 29.01 \\
$\begin{array}{l}11-2 \text { coal } \\
\text { Siltstone }\end{array}$ & 1743.23 & 2.75 & 56.528 & 6.705 & 0.216 & 23.08 & 38.01 \\
Fine siltstone & 2629.79 & 4.21 & 76.256 & 9.929 & 0.228 & 30.26 & 32.32 \\
\hline
\end{tabular}

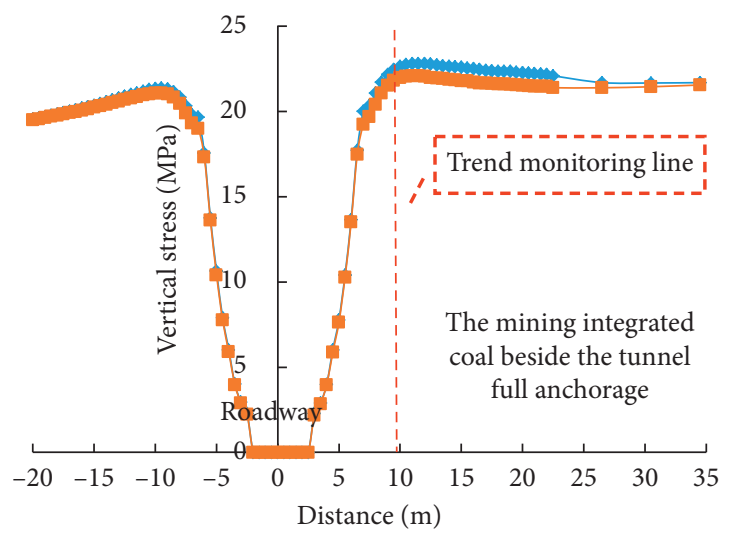

$\rightarrow-$ Full anchorage

- End anchorage

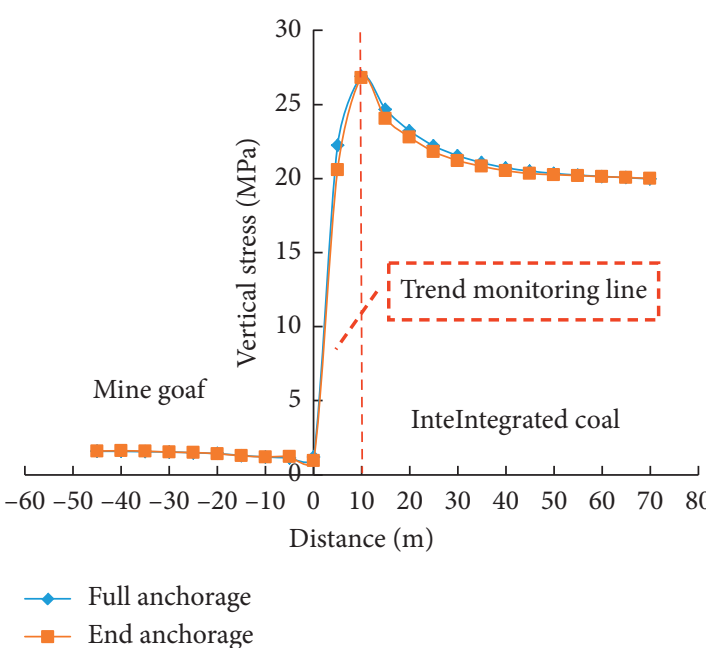

(b)

(a)

FIgURE 5: Vertical stress variation at different positions of the tunnel. At $12 \mathrm{~m}$ in the (a) front of incline working face and (b) mining coal beside the tunnel.

multipoint displacement meter are used to monitor the deformation of surrounding rock of roadway, as shown in Figure 7. Combined with the monitoring results of two test areas, representative deformation data of surrounding rock and monitoring data of force-measuring bolt are selected for comparative analysis.
5.1. Force Variation in Bolts under Different Anchorages. The variation pattern of the axial force in the force-measuring bolt within the end-anchorage experimental area is shown in Figure 8. It can be seen that the evolution trends of the axial force of roof and side bolts were the same, which was consistent with the laboratory results. The axial force of 

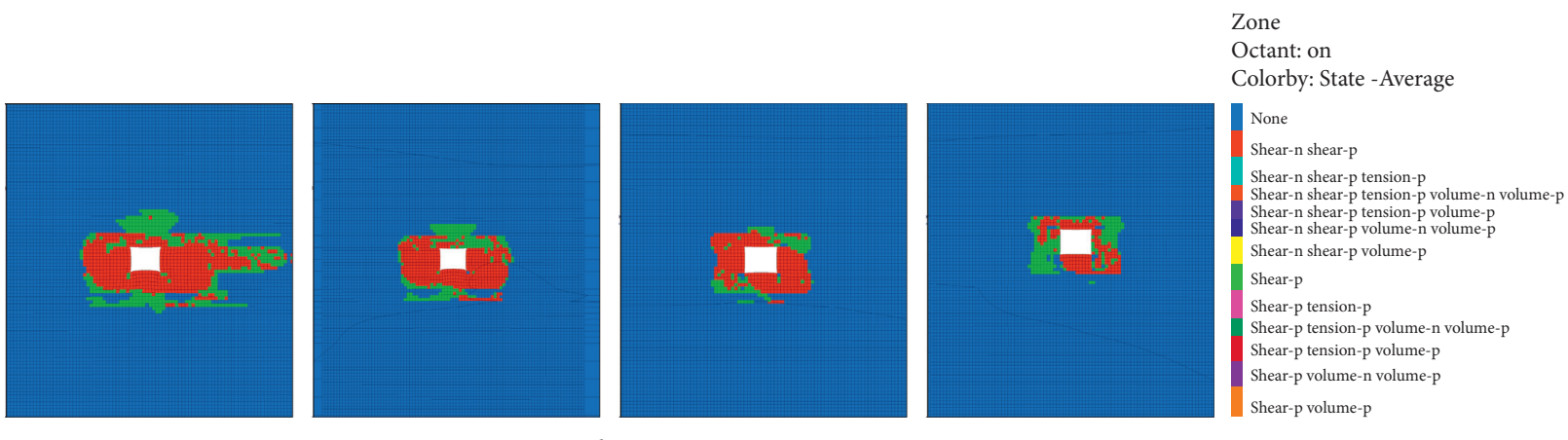

Condition 1

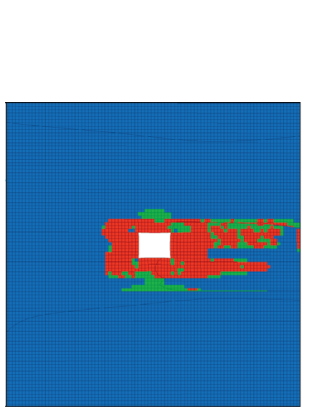

(a)

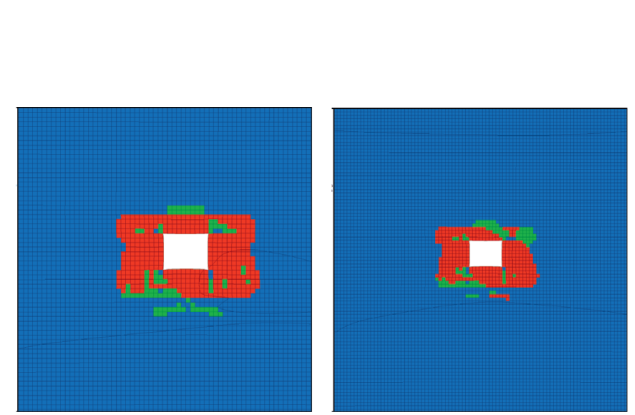

Condition 2

(b)

(c)

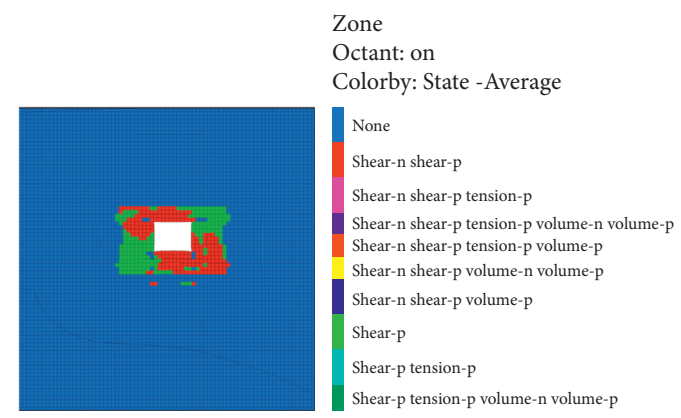

(d)

FIGURE 6: Damage distribution characteristics of the SR. (a) $5 \mathrm{~m}$. (b) $20 \mathrm{~m}$ (c) $30 \mathrm{~m}$. (d) $60 \mathrm{~m}$.
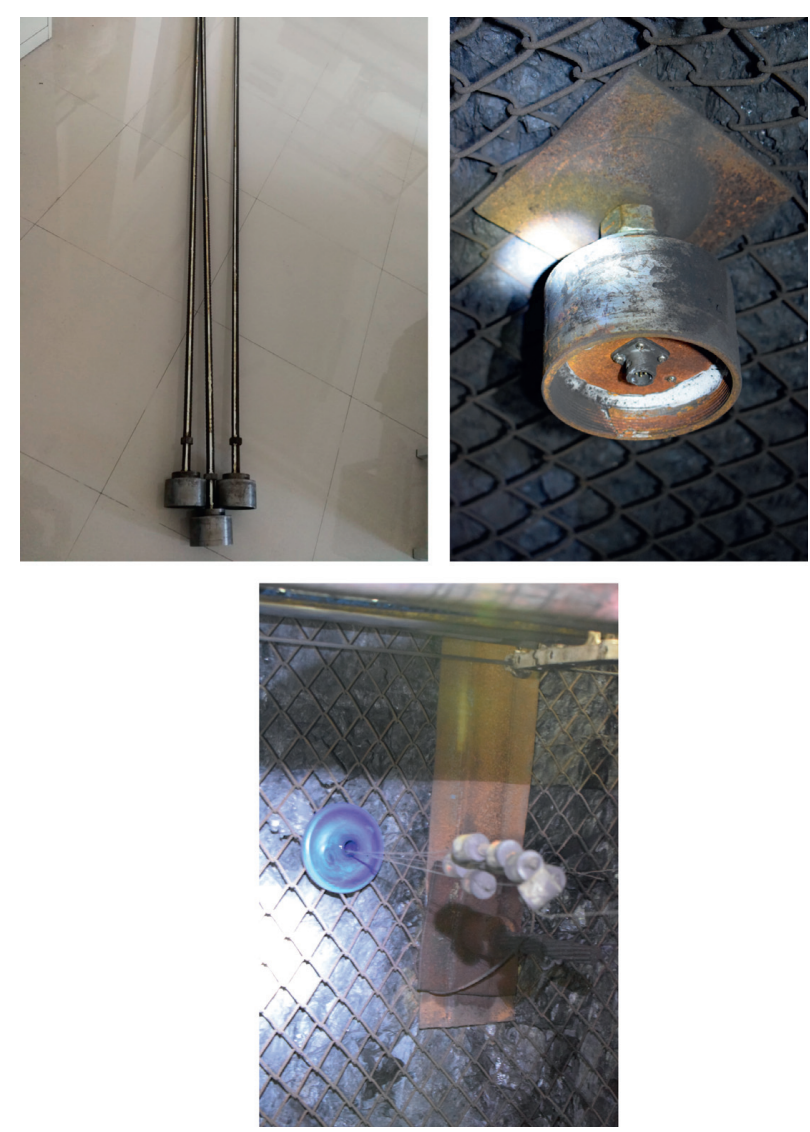

FigURE 7: Force-measuring bolts and multipoint displacement meters of the mining roadway. 


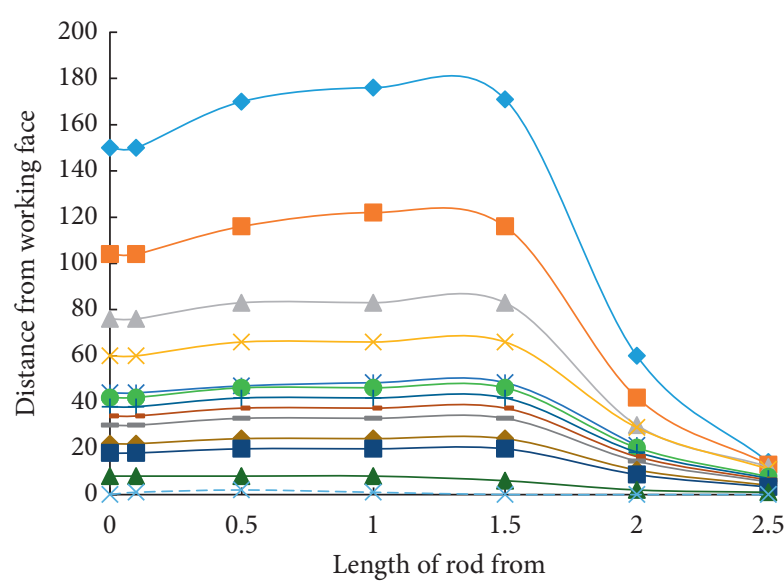

Distance from working face
$-37.4 \mathrm{~m} \rightarrow 109 \mathrm{~m} \rightarrow 161.1 \mathrm{~m} \rightarrow 215.7 \mathrm{~m}$
$-56.6 \mathrm{~m} \rightarrow 126.4 \mathrm{~m}-178.9 \mathrm{~m} \rightarrow 232.1 \mathrm{~m}$
$\rightarrow 73.5 \mathrm{~m} \rightarrow 144.9 \mathrm{~m} \rightarrow 196.6 \mathrm{~m} \rightarrow-\star-249.2 \mathrm{~m}$
$\times 90.2 \mathrm{~m}$

(a)

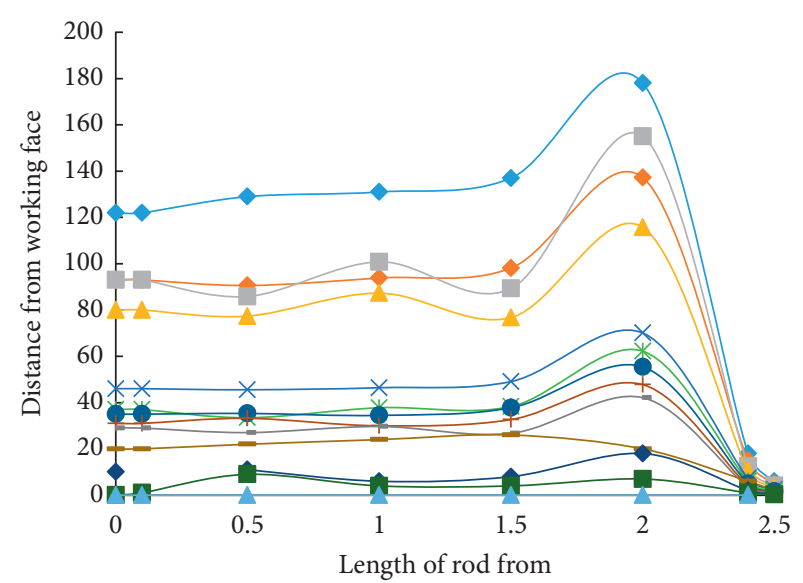

Distance from working face
$\multimap 23.8 \mathrm{~m} \rightarrow 130.1 \mathrm{~m} \rightarrow 194.6 \mathrm{~m} \rightarrow 256.7 \mathrm{~m}$
$\neg 44.7 \mathrm{~m} \rightarrow 152.5 \mathrm{~m} \longrightarrow 215.6 \mathrm{~m} \rightarrow 279.5 \mathrm{~m}$
$-66.0 \mathrm{~m} \rightarrow 172.7 \mathrm{~m} \longrightarrow 236 \mathrm{~m} \rightarrow-100.1 \mathrm{~m}$
$\rightarrow-87.8 \mathrm{~m}$

(b)

Figure 8: Variation pattern of the axial force of force-measuring bolt in the end anchorage zone. The axial force of the (a) roof rod body and (b) rod body.

the end-anchored bolt's free section was constant. As the working face advanced, the axial force in this area exhibited an overall increase; the anchoring agent bonded the axial force of the anchorage section of the rod body, and the axial force gradually decreased. Comparing the evolution curve of the axial force between force-measuring roof and side bolts, there is a "single-peak" increase in the axial force variation at the end of the side bolt. The reason is that the mining disturbances will produce corresponding SR deformation, so that there is certain friction between the rod body and the whole wall in this area (or the displacement and deformation of SR produce a shearing effect in the rod body). This causes the axial force of the rod body to fluctuate at that point and forms a "single peak" increase in the axial force of the endanchored bolt body.

The variation pattern of the axial force in the forcemeasuring bolt body in the full anchorage zone is shown in Figure 9. As observed, the axial force variation of the forcemeasuring side bolt in the full anchorage zone is different from that of the force-measuring roof bolt. The axial force variation curve has a single peak, that is, the maximum axial force appears near the middle of the full anchorage zone. The axial force at both ends of the full-anchored bolt is the smallest, which is consistent with the neutral point theory of the full-anchored bolt. As the working face advances, the SR is significantly deformed and displaced, and the axial force in the full-anchored bolt is also increased.

5.2. Deformation Rule of SR under Different Anchorages. The displacement pattern of SR under different anchorages was obtained by monitoring the displacement variations of full- and end-anchored SRs with different depths. The typical multipoint displacement curve of the tunnel side SR was selected for the SR stability analysis, as shown in Figures 10 and 11 .

When the measuring station is located about $150 \mathrm{~m}$ from the working face, roof rock displacements in the end- and full-anchored zones start to increase, indicating that the mining impact area of the working face was about $150 \mathrm{~m}$. As the working face advanced, the roof rock displacement continued to increase, where the increase range and rate of the displacement at each point of roof rock in the endanchored zone generally exceeded that in the full-anchored one. The maximum subsidence values of the roof surface at the end- and full-anchored zones reached 390 and $325 \mathrm{~mm}$, respectively. At $60 \mathrm{~m}$ in front of the working face, with the further advancement of the working face, the variation rate of the deep displacement of roof rock in the end-anchored zone doubled, with the maximum rate of about $27 \mathrm{~mm} / \mathrm{d}$. In contrast, one in the full-anchored zone was relatively stable, with a maximum rate of about $20 \mathrm{~mm} / \mathrm{d}$. Therefore, the full anchorage was more conducive to the movement control of the roof rock.

\section{Discussion}

In the indoor drawing experiment, the synergistic deformation effect of SR and bolt body cannot be achieved, which makes the axial force distribution characteristics of rod body measured in the field test under different anchorages much different from the indoor drawing experiment results. The deep mining roadway is affected by mining disturbances, and its SR continues to experience various forms of 

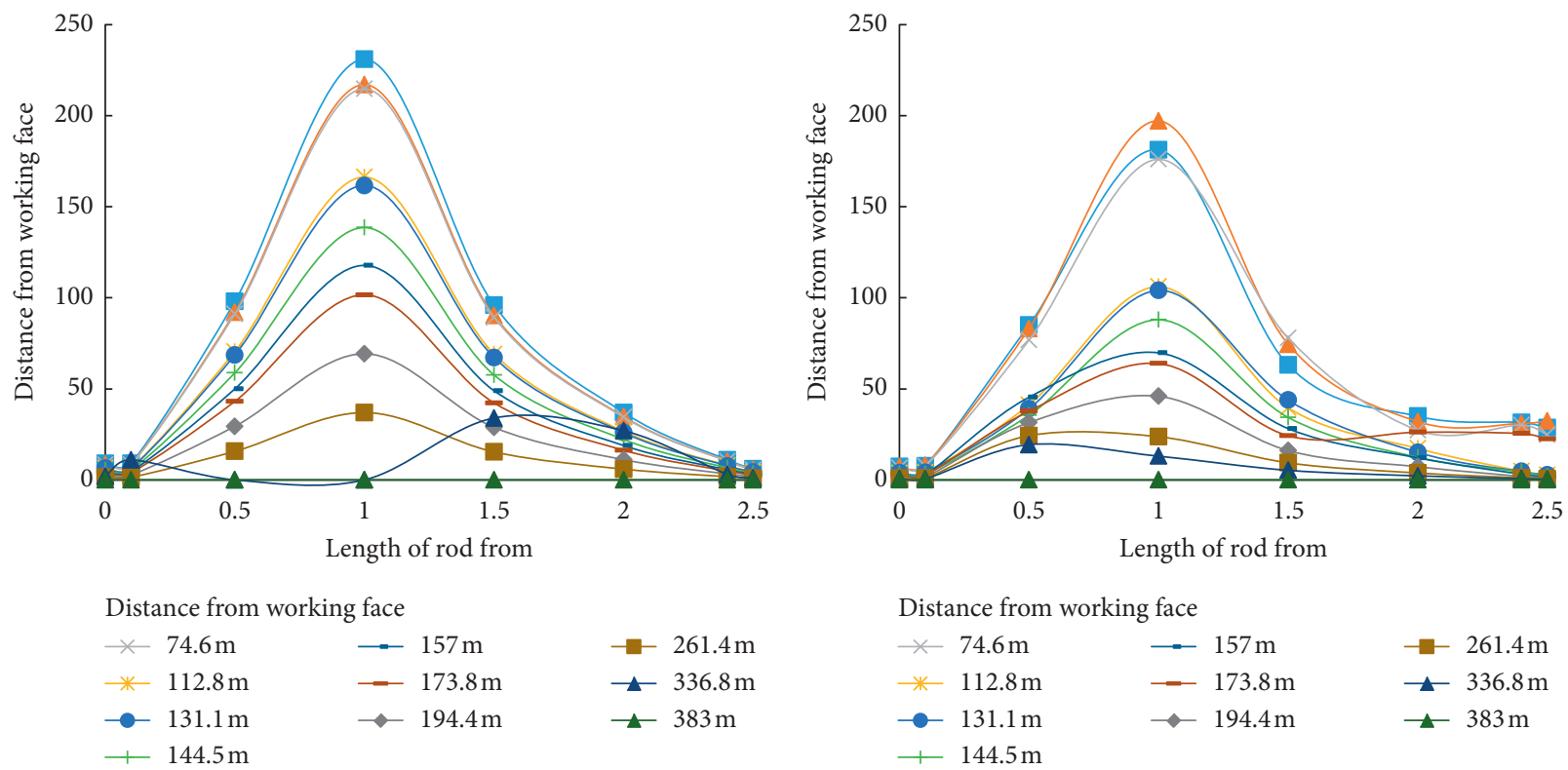

(a)

(b)

FIgURE 9: Variation pattern of the axial force in the force-measuring bolt within the full anchorage zone. The axial force in the (a) roof rod body and (b) side rod body.

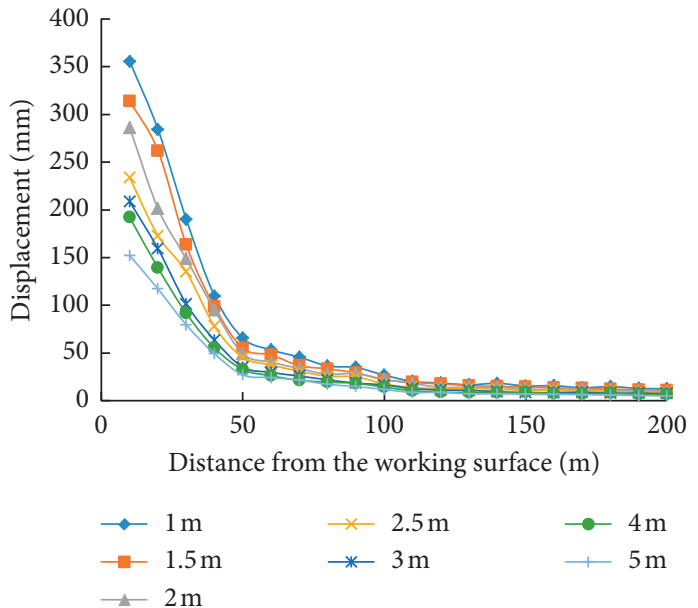

(a)

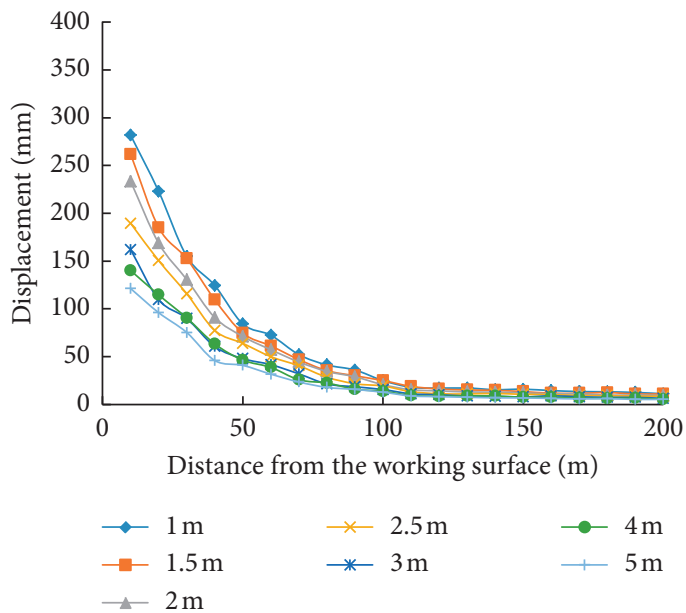

(b)

FiguRE 10: Displacement curve of roof country rocks in different anchorage zones. (a) End anchorage. (b) Full anchorage.

deformation, which causes changes in the force of the SR support bolt. The comparative analysis of numerical simulation results revealed that within a certain range in front of the working face, the vertical stress and the axial force in the integrated coal under full anchorage working conditions were slightly higher than those under the end one. As the mining disturbances grew, the deformation and damage range of the fully and end-anchored SR continued to increase, but the range of end-anchored SR plastic failures was significantly larger. According to the SR displacement monitoring in the field test area, the deformation of full-anchored SR was less than that of the end one. In the area where the stress was severely affected in front of the working face, the deformation rate of full-anchored SR was small, indicating that full-anchored SR had stronger energy absorption and deformation resistance, which was more conducive to the SR stability. 


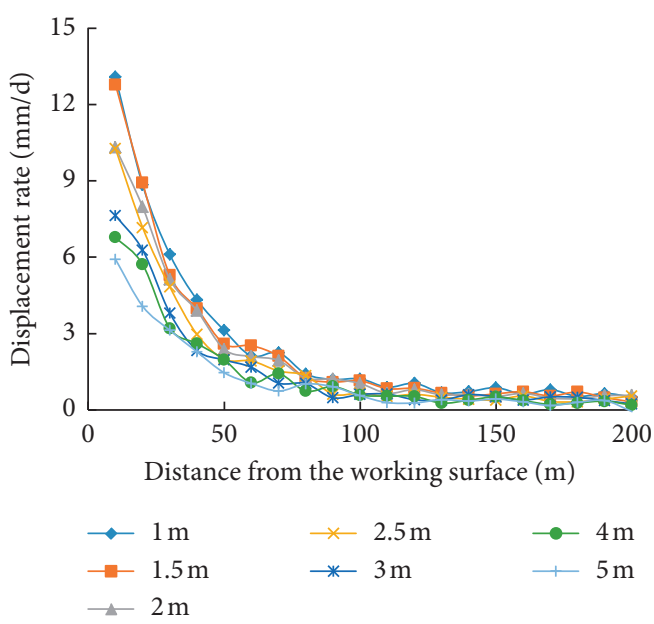

(a)

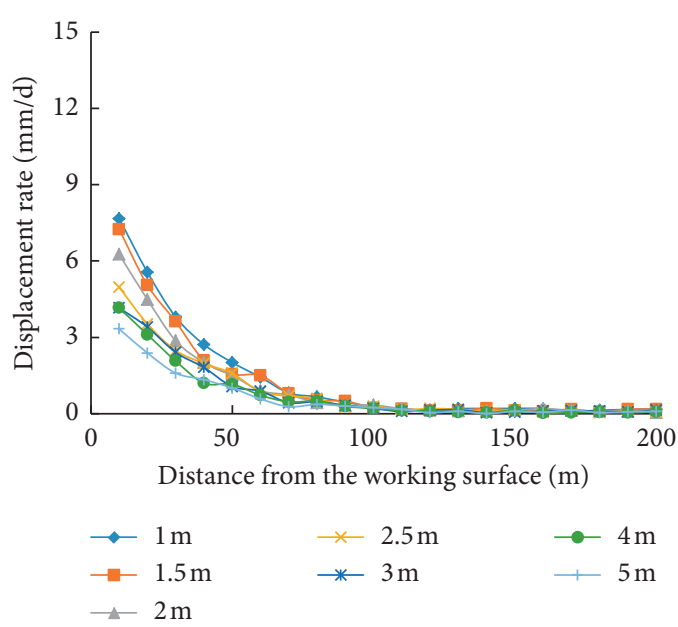

(b)

FIGURE 11: Displacement change rate of roof country rocks in different anchorage areas. (a) End anchorage. (b) Full anchorage.

\section{Conclusions}

The axial force distribution characteristics of full- and endanchored bolt bodies were obtained via indoor drawing tests and on-site comparative tests. The bearing characteristics of deep mining roadway SR were simulated using the FLAC3D software. The variation patterns of vertical stress in different tunnel locations and the damage distribution characteristics of the SR were studied and verified on-site. The conclusions are as follows:

(1) The comparison of the field and indoor drawing test results shows that they have the same variation trend of the axial force for the end-anchored bolts, in contrast to the full-anchored bolts. The reason is that the polymorphic deformation of the deep mining roadway SR is synchronized with the bolt support.

(2) Full-anchored SRs bear higher stresses than the endanchored ones and reduce the degree of stress concentration. The stress distribution trends on both sides of the mining roadway are the same. Still, the vertical stress peak of full-anchored SR is slightly higher than that of end-anchored ones, and the damage range is smaller.

(3) The actual measurements revealed that with the strengthening of mining disturbances, the deformation of full-anchored SR exhibited an overall increasing trend. Still, the rate is relatively slow, while the deformation of end-anchored SR had a sharp increase. This proves that full-anchored SRs are more conducive to the control of deformation and movement of the tunnel side rock.

\section{Data Availability}

The data used to support the findings of this study are included within the article.

\section{Conflicts of Interest}

The authors declare that they have no conflicts of interest.

\section{Acknowledgments}

The authors gratefully acknowledge the support from the Natural Science Foundation of Anhui Province (2008085QE226) and School Level Scientific Research and Innovation Team of Huainan Normal University (XJTD202009).

\section{References}

[1] Y. Xu, D. J. Williams, and M. Serati, "Influence of anchorage angles on pull-out resistance of geotextile wrap around anchorage," Geosynthetics International, vol. 25, no. 4, pp. 378-391, 2018.

[2] Q. Qian and X. Zhou, "Failure behaviors and rock deformation during excavation of underground cavern group for jinping I hydropower station," Rock Mechanics and Rock Engineering, vol. 51, no. 8, pp. 2639-2651, 2018.

[3] Y. Chen, W. Zhu, S. Li, and X. Zhang, "New reinforcement algorithms in discontinuous deformation analysis for rock failure," Geomechanics and Engineering, vol. 11, no. 6, pp. 787-803, 2016.

[4] Y. Han, X. Liu, D. Li et al., "Model test on the bearing behaviors of the tunnel-type Anchorage in soft rock with underlying weak interlayers," Bulletin of Engineering Geology and the Environment, vol. 79, no. 2, pp. 1023-1040, 2020.

[5] Z. Guo, L. Zhang, H. Wang, S. Yin, T. Li, and X. Kuai, "Failure mechanism of bolts and countermeasures in swelling soft rock support," Tehnicki Vjesnik-Technical Gazette, vol. 25, no. 5, pp. 1447-1456, 2018.

[6] H. Yang, C. Han, N. Zhang, Y. Sun, D. Pan, and C. Sun, "Long high-performance sustainable bolt technology for the deep coal roadway roof: a case study," Sustainability, vol. 12, no. 13754, 2020.

[7] Q. Wang, Q. Qin, B. Jiang, H. C. Yu, R. Pan, and S. C. Li, "Study and engineering application on the bolt-grouting reinforcement effect in underground engineering with fractured surrounding rock," Tunnelling and Underground Space Technology, vol. 84, pp. 237-247, 2019.

[8] S. Seunghwan, J. Park, S. Lee, and M. Chung, "Analysis of pull-out behavior of tunnel-type anchorage for suspended bridge using 2-D model tests and numerical analysis," Journal 
of the Korean Geotechnical Society, vol. 34, no. 10, pp. 61-74, 2018.

[9] P. Marini and R. Bellopede, "Bowing of marble slabs: evolution and correlation with mechanical decay," Construction and Building Materials, vol. 23, no. 7, pp. 2599-2605, 2009.

[10] A. R. Akisanya and A. Ivanović, "Debonding along the fixed anchor length of a ground anchorage," Engineering Structures, vol. 74, pp. 23-31, 2014.

[11] J. Hofmann, F. Dwenger, A. Sharma, and K. Kerkhof, "Verschiebungsverhalten von Hinterschnittdübeln unter Zuglast bei Rissöffnen und -schließen," Beton-Und Stahlbetonbau, vol. 115, no. 1, pp. 54-61, 2020.

[12] Z. Huang, M.-Y. Zhang, and X.-Y. Bai, "Load-bearing characteristics of fibreglass uplift anchors in weathered rock," Proceedings of the Institution of Civil Engineers-Geotechnical Engineering, vol. 173, no. 1, pp. 49-57, 2020.

[13] Z. Zhao, Q. Ma, Y. Tan, and X. Gao, "Load transfer mechanism and reinforcement effect of segmentally yieldable anchorage in weakly consolidated soft rock," Simulation, vol. 95, no. 1, pp. 83-96, 2019.

[14] D. Chen, Q. Zhang, S. Xie et al., "Combined support technology for main roadway passing through goaf: a case study," Energy Science \& Engineering, vol. 8, no. 5, 2020.

[15] B. Wang, X. Guo, F. Li, D. Hu, and Y. Jia, "Mechanical behavior of rock bolts under a high temperature environment," International Journal of Rock Mechanics and Mining Sciences, vol. 104, pp. 126-130, 2018.

[16] J. Tian and L. Hu, "Anchorage performance of a high-pressure pre-tightening resin anchor with a compressed grouting body," Plos One, vol. 12, Article ID e01716532, 2017.

[17] N. Zhang, C. Wang, X. L. Xu, and Y. M. Zhao, "Argillisation of surrounding rock due to water seepage and anchorage performance protection," Materials Research Innovations, vol. 15, no. sup1, pp. S582-S585, 2011.

[18] M. Liang and X. Fang, "Application of fiber bragg grating sensing technology for bolt force status monitoring in roadways," Applied Sciences-Basel, vol. 8, no. 1, 107 pages, 2018.

[19] H. Ma, X.-H. Tan, J.-Z. Qian, and X.-L. Hou, "Theoretical analysis of anchorage mechanism for rock bolt including local stripping bolt," International Journal of Rock Mechanics and Mining Sciences, vol. 122, Article ID 104080, 2019.

[20] X. Lyu, Z. Zhao, Q. Ma, X. Wang, and X. Gao, "2D semimodel of full-section anchorage in thick soft rock roadway," Shock and Vibration, vol. 2018, Article ID 9853853, 15 pages, 2018.

[21] K. Nagai, D. Hayashi, and L. Eddy, "Numerical simulation of failure of anchorage with shifted mechanical anchorage bars by 3D discrete model," Advances in Structural Engineering, vol. 17, no. 6, pp. 861-869, 2014.

[22] S. D. Sik, "Numerical analysis for the pullout test to estimate the optimum length of anchorage," Crisisonomy, vol. 8, no. 5, pp. 235-246, 2012.

[23] Y. Chen, J. Teng, R. A. Bin Sadiq et al., "Experimental study of bolt-anchoring mechanism for bedded rock mass," International Journal of Geomechanics, vol. 20, no. 4, 2020.

[24] Y. Zhao, N. Zhang, and K. Zheng, "Experimental study of axial stress distribution and transfer along the bolt rods in an underground coal mine," Arabian Journal of Geosciences, vol. 9, no. 301, 2016. 